\title{
When school comes home: How low-income families are adapting to distance learning
}

A report from the USC Rossier School of Education and the USC Annenberg School for Communication and Journalism

\section{October 2020}

\section{USCRossier}

USCAnnenberg 


\section{Table of Contents}

About 3

Foreword 4

Bridging the digital equity gap through policy _ـ 5

Introduction 6

The impact of the COVID-19 crisis is widespread _ 8

Distance Learning Infrastructure at Home _ـ 9

Technological resources for children _ 9

Investments in digital readiness at home _ 10

A quiet place for learning ___ 11

Support for Remote Learning _ 12

Barriers to parents as teachers _ 12

$\begin{array}{ll}\text { The role of family support } & 14\end{array}$

Remote Learning Outcomes _ 15

The role of live instruction _ـ 16

Student motivation _ 17

Better connectivity and devices boost engagement ___ 18

Live instruction helps math and English __ 19

Expectations for improving distance learning — 20

Conclusion and policy recommendations _ 21

Reflections for community engagement research 22

Using technology during community engagement in research — 24 


\section{About}

\section{PRINCIPAL INVESTIGATORS}

Stephen J. Aguilar

Assistant Professor, USC Rossier School of Education

Hernan Galperin

Associate Professor, USC Annenberg School for Communication and Journalism

\section{CONTRIBUTORS}

Pedro A. Noguera

Emery Stoops and Joyce King Stoops Dean of the USC Rossier School of Education

Alan Arkatov

Katzman/Ernst Chair for Educational Entrepreneurship, Technology and Innovation Founder, Center EDGE

Clare Baek

Ph.D. Student, USC Rossier School of Education

Eduardo Gonzalez

Ph.D. Student, USC Annenberg School for Communication and Journalism

\section{CITATION}

This report can be cited as:

Aguilar, S. J., Galperin, H., Baek, C., \& Gonzalez, E. (2020, October 14).

When school comes home: How low-income families are adapting to distance learning. https://doi.org/10.35542/osf.io/su8wk 


\section{Foreword}

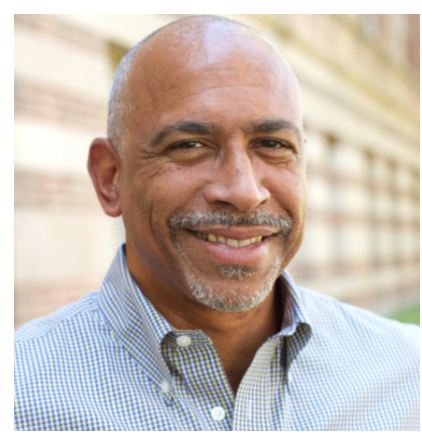

Education is the key to ensuring that all people have access to a promising future. Access to quality education is important to the future of our economy, the health and vibrancy of our democracy, and to social cohesion. Horace Mann, the first secretary of education in Massachusetts, put forward the idea that education could serve as an equalizer of opportunity. He saw that education could serve as the means to develop talents of citizens and to ensure that hard work rather than privilege was rewarded. Unfortunately, too often, our schools reproduce patterns of inequality and privilege.

The pandemic has exposed and exacerbated the preexisting inequalities we knew were there: the digital divide, the lack of a social safety net, and the fact that the parents of many school children are out of work and at risk to contracting the virus because they are "essential workers."

Fortunately, many of our schools have adapted. Hot spots and screen devices have been distributed, and many more children are now able to participate in remote learning than in the spring. However, recent news shows that some distance learning measures have put additional strain on families and teachers, and many children are experiencing significant losses in learning. As a result of these challenges, our ability to make good on the promise of education for the neediest of our students is in doubt.

Now, the question is what can we do about it? This report is a step in the right direction. It brings to light challenges that have been faced by families in Los Angeles; challenges that we must face and overcome together.

Despite the challenges that this report sheds light upon, we cannot allow legitimate concerns about logistics related to the safe operation of schools be all that we think about. We must recognize that schools are still critical to the economy, and if we want the future of Los Angeles to be less characterized by profound inequality, we must do more to guarantee high quality learning opportunities for all children.

Our kids must be prepared to thrive and think in an uncertain world. In school they should not only receive social and emotional support, they should also experience the joy of learning. This is why this report is so important. It reminds us of how far we must go to deliver a well-rounded education that includes the arts, physical education and nutrition to all kids. To secure our future we must work together now to ensure this type of education is available to all.

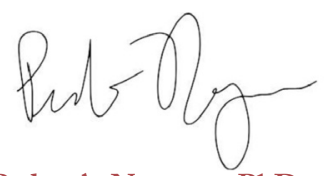

Pedro A. Noguera, PhD

Emery Stoops and Joyce King Stoops Dean USC Rossier School of Education 


\title{
Bridging the digital equity gap through policy
}

\section{USCRossier}

School of Education

Center for Engagement-Driven Global Education (EDGE)

\author{
Alan Arkatov \\ Katzman/Ernst Chair for Educational Entrepreneurship, Technology and Innovation \\ USC Rossier School of Education, Founder, Center EDGE
}

Since 2001, Federal law has required that K-12 schools annually assess and report on the performance of students and present the results not just as a whole but disaggregated by race, income, and disability status. That change has ushered in a wave of academic assessment and research-based decision making, and documented for policymakers the gaps between low income students and their more affluent peer group, racial minorities and their white peer group, English language learners and peers for whom English is spoken at home, and the challenges faced by students with cognitive disabilities. On a parallel but largely unconnected track, academics concerned with the internet as a transformative technology have sought to measure the availability and affordability of internet service across the U.S. and internationally.

When entire school districts shuttered in March 2020 due to the COVID-19 pandemic, these parallel paths had not yet converged to posit the extent to which the challenge of delivering instruction online would also be steeper for students in low income and minority households. As has been widely documented through social and traditional media, K-12 schools were confronted with a near total absence of infrastructure for home instruction. Prior to March most schools had never adopted online learning software, trained educators to use those platforms, determined if students and teachers had access to dedicated computers or tablets at home, or asked if students and teachers had home internet service capable of supporting video and live instructional content.

School and school district leaders were thrust into building that infrastructure while mapping and driving on it, while students and families were told that they needed to adapt immediately to the new world order of learning entirely outside of school, which quickly exposed the giant gaps in the necessary resources that are often dependent on income level and location. The current report adds to the mounting evidence about gaps in student readiness for distance learning. Similar findings emerged from an earlier USC Rossier Center EDGE nationwide survey conducted this summer in collaboration with Frank Luntz and with funding from the Chan Zuckerberg Initiative.

These and other studies point to the need to address the disparities in educational outcomes that are being dramatically exacerbated by the pandemic as a result of the digital divide. They call for immediate policy action at the local, state and federal levels to address this fundamental inequality that threatens our educational system. 


\section{Introduction}

Stephen J. Aguilar

Assistant Professor of Education, USC Rossier School of Education

[We must be] able to live with and toward others, to recognize and show concern for other humans, to engage in various forms of social interaction; to be able to imagine the situation of another.

- Martha Nussbaum, Creating Capabilities

Access to a good education is not only a public good, it is the right of every American. Yet, the necessary move to distance learning has shown how precarious enacting this right is in time of pandemic-induced emergency. My collaborators and I have written this report to highlight how families within Los Angeles have coped with the imposition of distance learning. It shows that despite difficulties, families within the Los Angeles Unified School District (LAUSD) have found ways to ensure that their children can still access the educational resources provided by LAUSD.

Our report also highlights, however, digital equity gaps that threaten to undermine students' learning progress this academic year. At the heart of this project is the idea that now more than ever, educators, researchers, policy makers, and the public at large must work hard to not only close digital equity gaps, but also need to work hard to close gaps in understanding, so that policies that are put in place to help students do so with a holistic framework, one that recognizes that distance learning is as much predicated on infrastructure as it is on technological devices.

\section{Context and methodology}

School campus closures due to COVID-19 forced the transition to remote learning in March 2020, which continues in fall 2020 and will likely continue through spring 2021. Remote learning measures present multiple challenges for low-income, minority families, and these families have been disproportionately affected by the COVID-19 crisis. We sought to understand the challenges they faced, including the lack of internet access and devices, digital skills and lack of appropriate learning space at home.

We sampled families with children in K-12 schools administered by the Partnership for Los Angeles Schools, Vaughn Next Century Learning Center, and STEM Preparatory Schools. In total, these LAUSD schools serve about 17,500 students. Our final sample size was 1,971 families. Data were gathered both via telephone (LA Partnership schools) and self- administered web survey (Vaughn and STEM-Prep schools). Surveys were administered in English and Spanish to parents or legal guardian who were over 18 years old. The average survey duration was 18 minutes. (Fieldwork dates: July 8, 2020 - August 21, 2020.) 


\section{Introduction}

\section{Summary of findings}

The realities due to the COVID-19 pandemic have caused schools and families to adapt quickly to find solutions to the challenges posed by distance learning. With funding from Great Public Schools Now, we reached out to families to better understand how they are coping with distance learning. This report outlines what we have learned about the challenges to remote learning among disadvantaged students during the March-June 2020 period.

We examined student engagement and learning outcomes in the wake of the COVID-19 crisis in order to identify the factors that have affected student motivation and achievement in distance learning. We also sought to identify pedagogical and communication strategies most effective to address remote learning challenges. We provide recommendations to improving remote learning outcomes in the 2020-21 school year and beyond, and hope to inform policy debates about federal, state and local initiatives to better support schools during COVID-19.

This study shows that the impact of COVID-19 is widespread among these families, with 58\% reporting food insecurity and $71 \%$ reporting loss of income. Despite these challenges, we find that families have made great sacrifices to improve digital readiness at home. Unfortunately, lack of reliable internet and limited access to appropriate devices is associated with lower student engagement, lack of motivation and lower schoolwork completion. Our findings also show that support from parents is often limited due to unfamiliarity with digital technologies, and that the digital divide threatens to exacerbate motivation and performance gaps. School support for internet access and devices - as well as live instruction and teacher feedback — is critical for improving remote learning in 2020-21.

To that end, our report is organized around four central themes. First, we examine the distance learning infrastructure that was in place in the homes during the abrupt shift to distance learning in spring 2020. This includes access to devices and to the internet. We then examine the support for remote learning families and students were offered, followed by an examination of remote learning outcomes reported by families. Finally, we examine parents' expectations for improving remote instruction in the 2020-21 school year.

The final pages of this report offer reflections from our graduate students who participated in the study. Eduardo Gonzalez, a Ph.D. student at the USC Annenberg School for Communication and Journalism offers reflections and recommendations for community engagement research. Clare Baek, a Ph.D. student at the USC Rossier School of Education, offers her reflections on using technology during community engagement in research. 


\section{The impact of the COVID-19 crisis is widespread}

We surveyed families with children in K-12 schools administered by the Partnership for Los Angeles Schools, Vaughn Next Century Learning Center, and STEM Prep. Overall, we find that the vast majority of families reported challenges in employment (71\%) and food security (58\%). Other difficulties in housing (15\%) and health (25\%) were also reported.

These findings point to the widespread nature of how COVID-19 impacted families during the outset of the pandemic (March through June). Thus, while the majority of this report focuses on the how LAUSD families adapted to emergency distance learning measures, it is important to highlight that such adaptation happened while other challenges were being faced by families.

\section{Since schools have been closed, have you and/or your family experienced challenges in any of the following areas?}

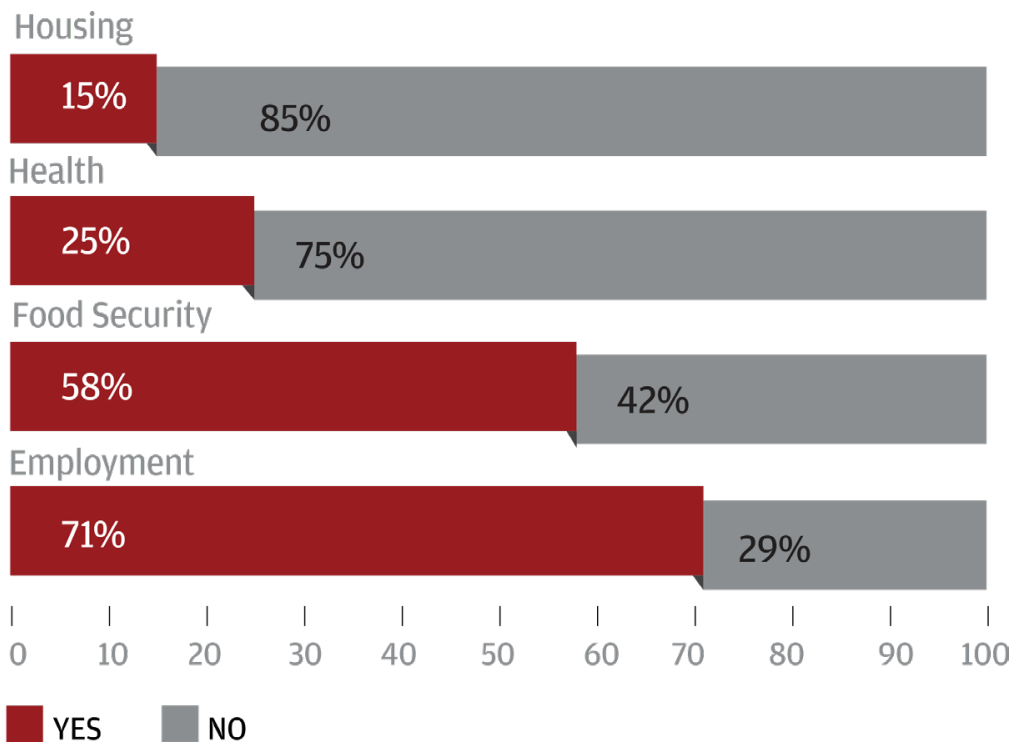




\section{Distance Learning Infrastructure at Home}

Remote learning has turned living rooms and bedrooms into classrooms. Yet, families need more than physical space to ensure that their children have an appropriate learning environment - they must also have the technology required to access the learning resources being provided by schools. Physical space, technology, parents, and siblings thus come together to create the classroom in the home. We term this "distance learning infrastructure," and asked LAUSD families how they adapted their homes to become classrooms for their children.

\section{Technological resources for children}

Distance learning has created multiple types of learning environments, all of which are mediated through the technologies students have access to. A student on a laptop who logs into a zoom meeting, for example, will have a very different experience when compared to a student who logs in with a tablet or mobile device. Given the potential disparities this creates, we sought to better understand what devices were present in the homes of LAUSD families.

Our results show that the majority of families reported their children using PCs or laptops for remote instruction. However, close to $20 \%$ of elementary school students used some other device to access remote instruction. We also asked families if devices were shared, since in the context of remote learning a shared device could mean missing out on a live class or less time for completing school activities. Of the families surveyed, $18 \%$ reported that the primary device used for remote learning was shared with other family members.

\section{Which device does your child typically use for distance learning?}

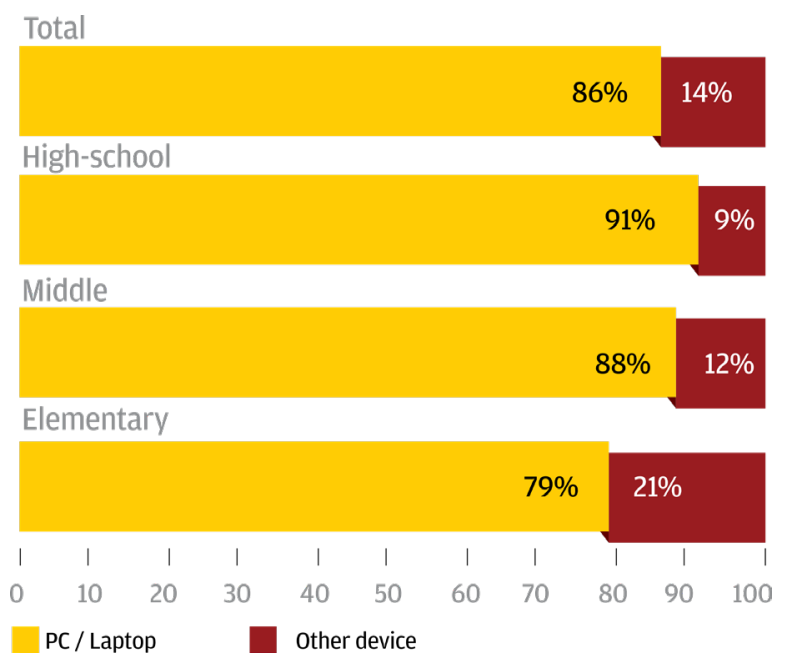




\section{Distance Learning Infrastructure at Home}

\section{Investments in digital readiness at home}

When schools abruptly transitioned to remote learning in spring 2020, many families found themselves on the wrong side of the digital divide. Our study has found that despite the economic hardships associated with COVID-19, many of these low-income families have greatly sacrificed to allow children to continue learning at home. About 1 in 3 families report buying a new device (such as a laptop) or a new internet access service to accommodate the distance learning needs of their children. The fact that these hard-hit families are making investments in digital readiness speaks volumes about the value they place on education. However, it also highlights the need for school districts to step up their efforts and ensure that, during the COVID pandemic, public education remains available to all regardless of income or wealth.

Since March, have you bought new devices or services for remote learning?

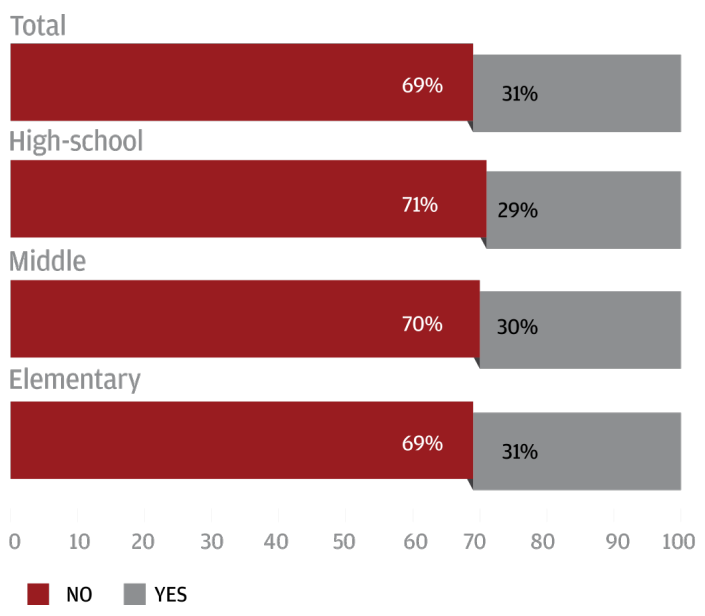

\section{Which device/ service did you buy?}

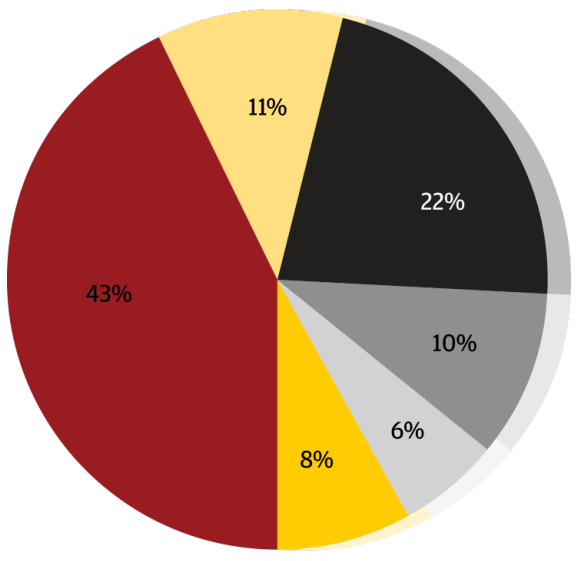
Cellphone
Tablet
Laptop / PC
Other
Fixed Internet
Mobile plan 


\section{Distance Learning Infrastructure at Home}

\section{A quiet place for learning}

Finding a quiet place for learning at home free of noise or distraction is often one of the key challenges for disadvantaged students. In order to support the learning needs of their children, many families report creating dedicated spaces in living rooms or bedrooms for their children to access remote learning content. Despite these efforts, the realities of the housing crisis in California are difficult to escape. Only about 1 in 3 families report that their children always have a place free of distraction for remote learning. This creates yet another challenge for remote instruction among disadvantaged students, who have to cope with distractions and interruptions while attending a remote live class or doing homework.

On a typical school day, did your child have a space free of noise or distraction for remote learning?

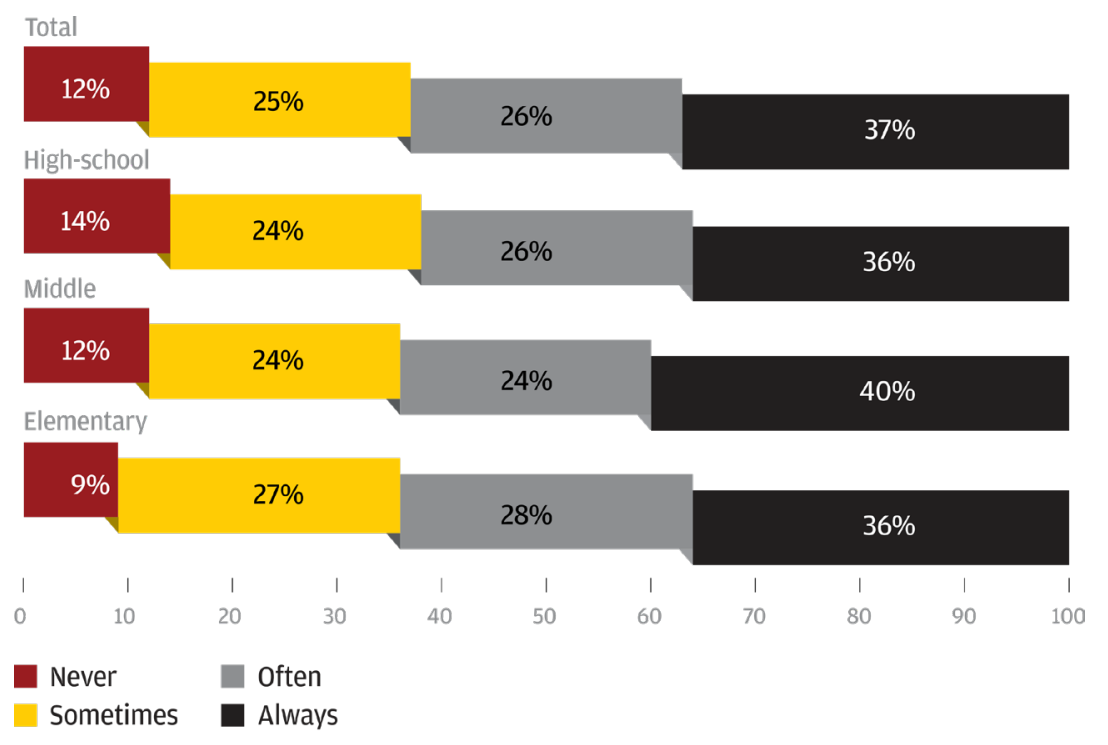




\section{Support for Remote Learning}

Students are more likely to stay engaged and succeed when parents actively participate in their education. This has taken an entirely different meaning during remote learning, which is premised on the idea that parents are present at home and ready to help students with school activities or troubleshoot problems connecting to the internet or logging into a class. While these multiple roles (parent, teacher, tech support) are difficult for any parent to accommodate, they are particularly difficult for low-income Black and Hispanic families who are struggling to accommodate the demands of schooling at home while at the same time grappling with fundamental challenges to health, employment and food security.

\section{Barriers to parents as teachers}

Limitations to human capital is one the many challenges for parents to effectively support their children during remote instruction. About half of the parents in our study (52\%) have not completed high school. Further, while most use the internet on a regular basis, the majority of parents have limited experience with computing devices. This reduces the ability to troubleshoot problems with connectivity and devices, which students (particularly younger ones) are often unable to address themselves. Consequently, support for remote learning falls largely on siblings and other members of the household.

\section{What is the highest educational level you have completed?}

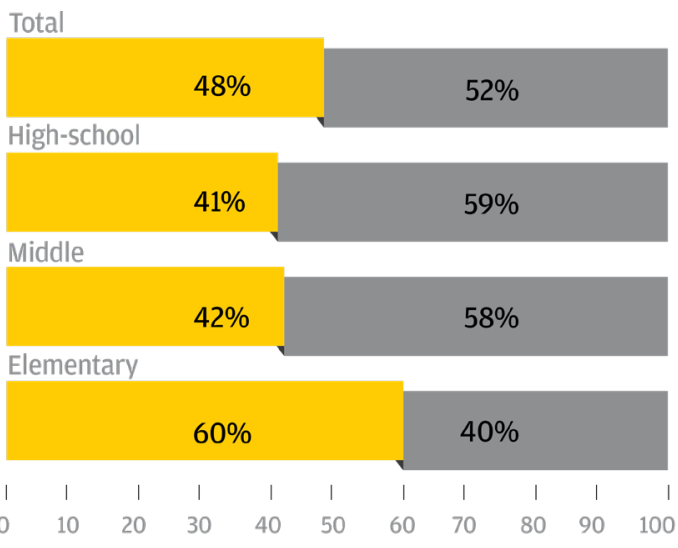

Completed high school
Not completed high school

\section{How often do you use a computer/ the Internet?}

Internet

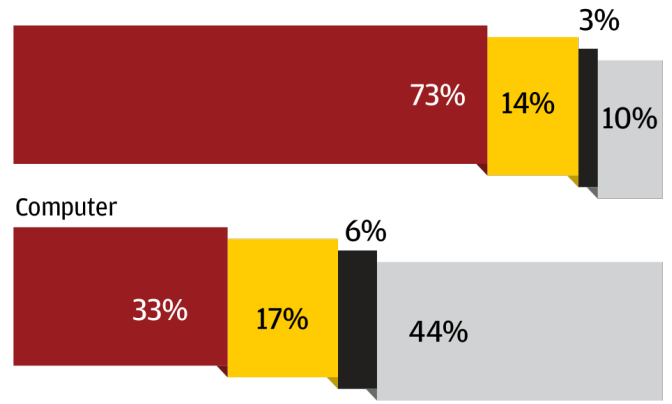

$\begin{array}{llllll}0 & 20 & 40 & 60 & 80 & 100\end{array}$

Every day

Every week

Few times a month

Never 


\section{Support for Remote Learning}

Another indication of this challenge is that parents report limited capacity to monitor their child's remote learning progress via the educational platforms that schools use to disseminate information and school activities (such as Schoology and Google Classroom). Overall, about a third of respondents reported never visiting these sites.

How often do you visit the sites that your child's school uses to support remote learning?

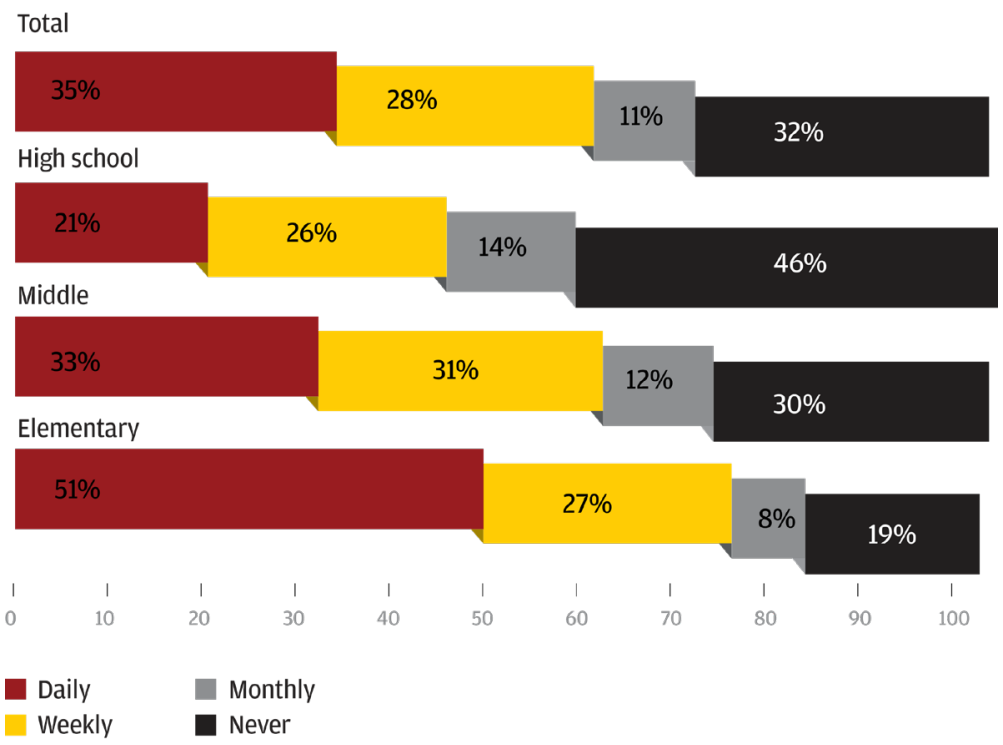




\section{Support for Remote Learning}

\section{The role of family support}

Older siblings and other family members, even when struggling to attend to school activities or work themselves, are playing a significant support role during remote instruction. This is particularly true for students beyond elementary grades. For students in middle school and high school, older siblings and other family members are who they turn to for school support and troubleshooting with connectivity and devices.

Who did your child ask for help when they had trouble with remote learning schoolwork?

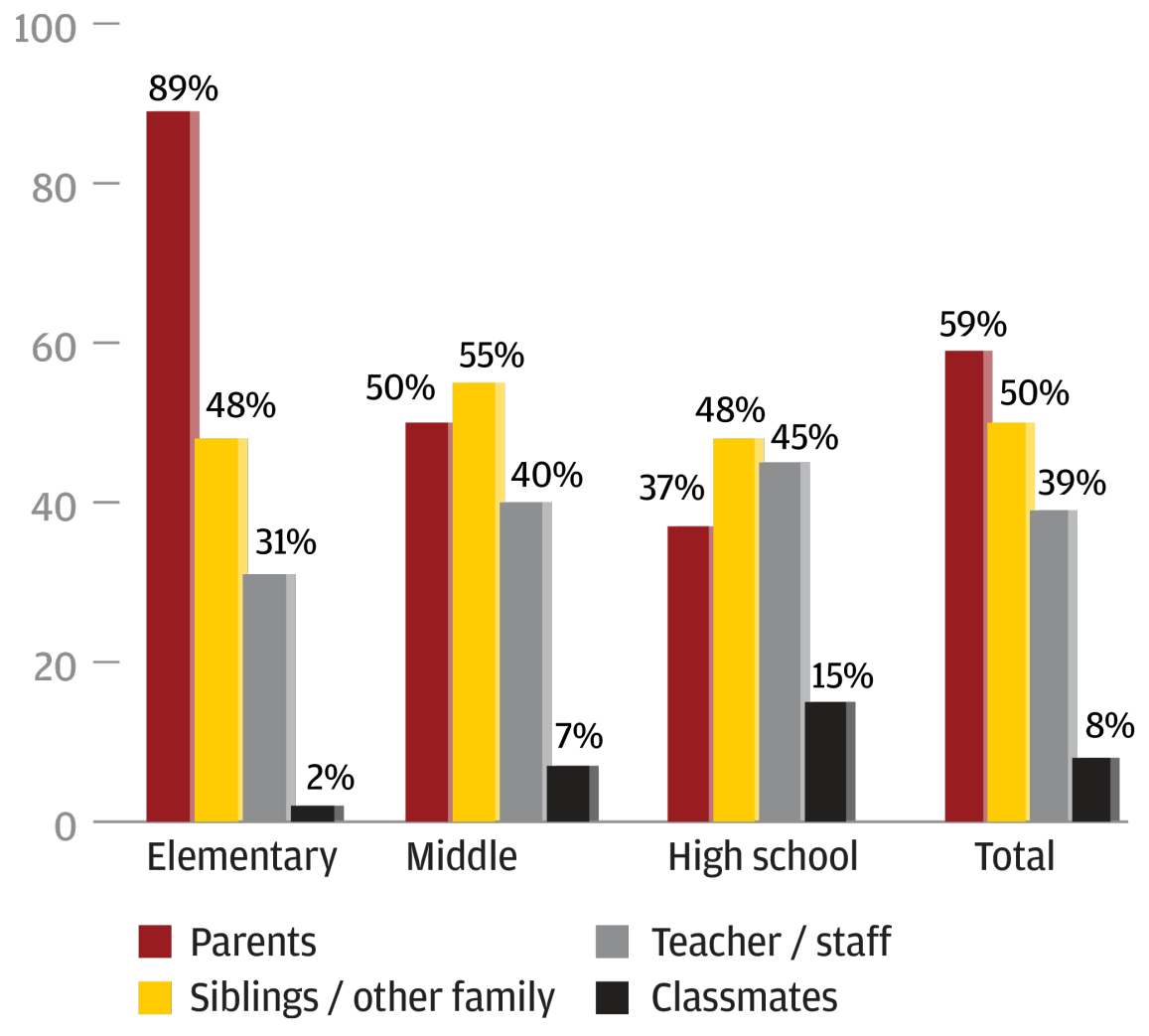

(Note : multiple answers possible) 


\section{Remote Learning Outcomes}

As part of the sudden shift to remote instruction in spring 2020, LAUSD and many other school districts decided that students would not be graded for work during this period. We thus use a number of imperfect proxies to measure learning outcomes as perceived by families. In other words, we use indirect measures of learning outcomes by asking families to report on schoolwork completion and student engagement.

Overall, about a third of the families report that their children were only able to complete "some but not all" of their school assignments. To better understand how differences in digital readiness affect completion, the results are disaggregated by the presence of different connectivity options and devices in the home. As shown, schoolwork completion is higher among families equipped with a PC device as well as among families with better connectivity.

\section{Since schools have been closed, how many school assignments was your child able to complete?}
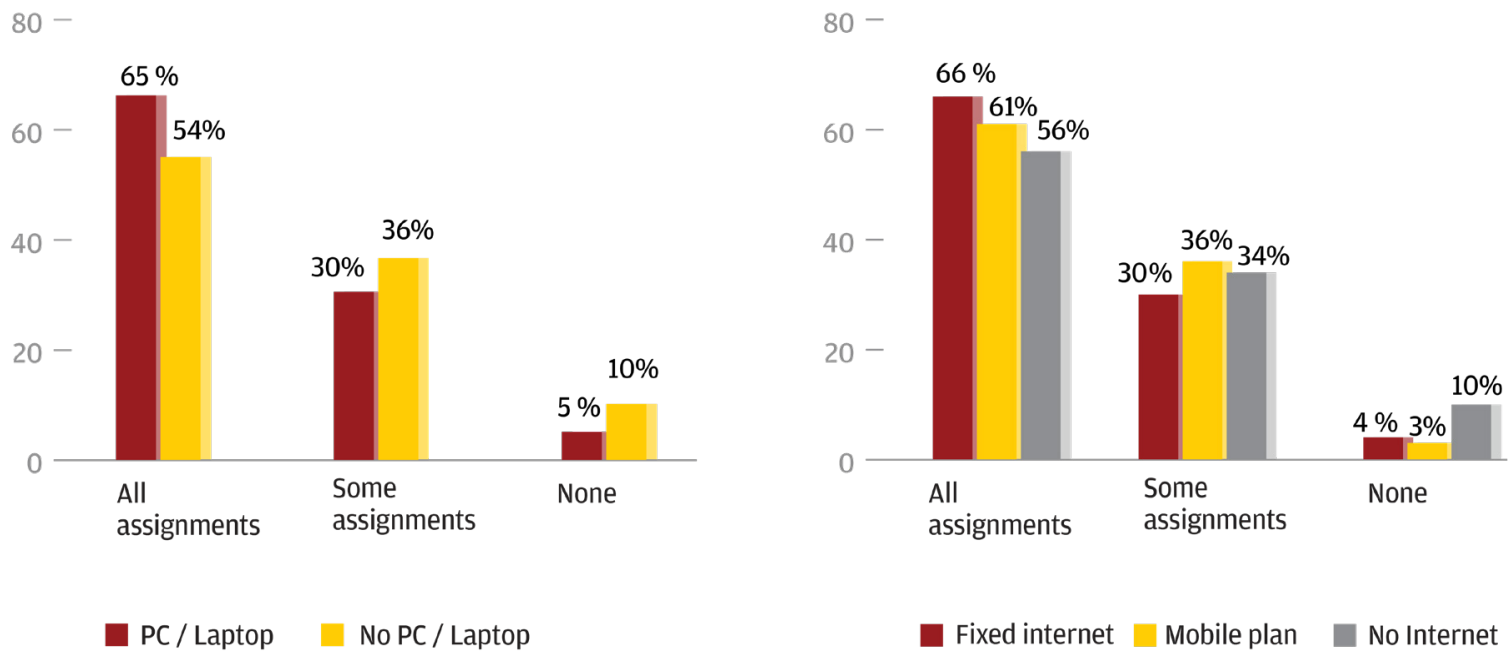


\section{Remote Learning Outcomes}

\section{The role of live instruction}

Live instruction is also associated with higher completion of schoolwork. As shown, as the reported number of live instruction hours increases, so does the reported rate of schoolwork completion. This finding corroborates the importance of supporting live instruction in remote learning modalities.

\section{Assignments completed by hours of live instruction}

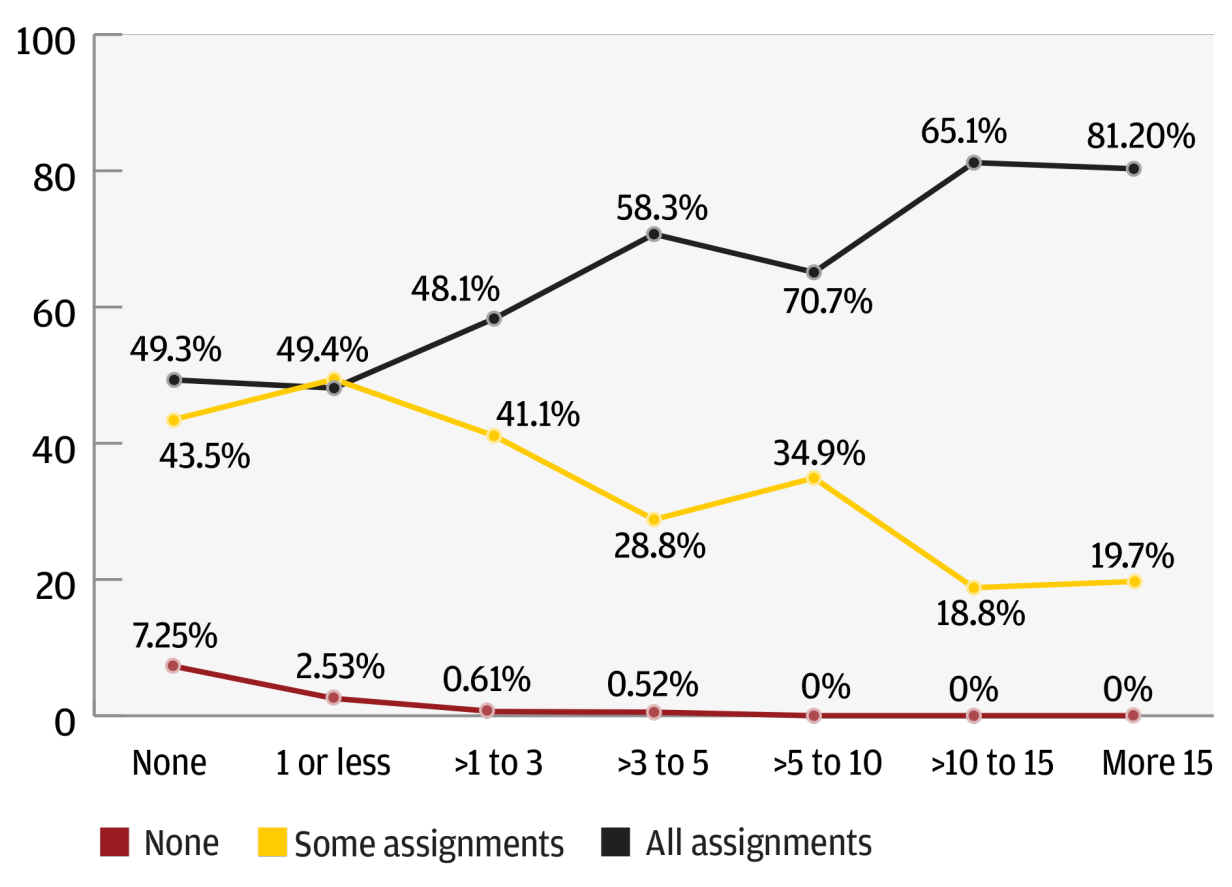




\section{Remote Learning Outcomes}

\section{Student motivation}

Student motivation is a critical input for academic success. When probed about barriers for schoolwork completion, families point to lack of motivation and limited school support as key factors. Both motivation and lack of school support were reported more often among high school students, suggesting that more support may be needed during remote instruction to students who otherwise would be self-sufficient.

\section{What prevented your child from completing schoolwork during remote learning?}

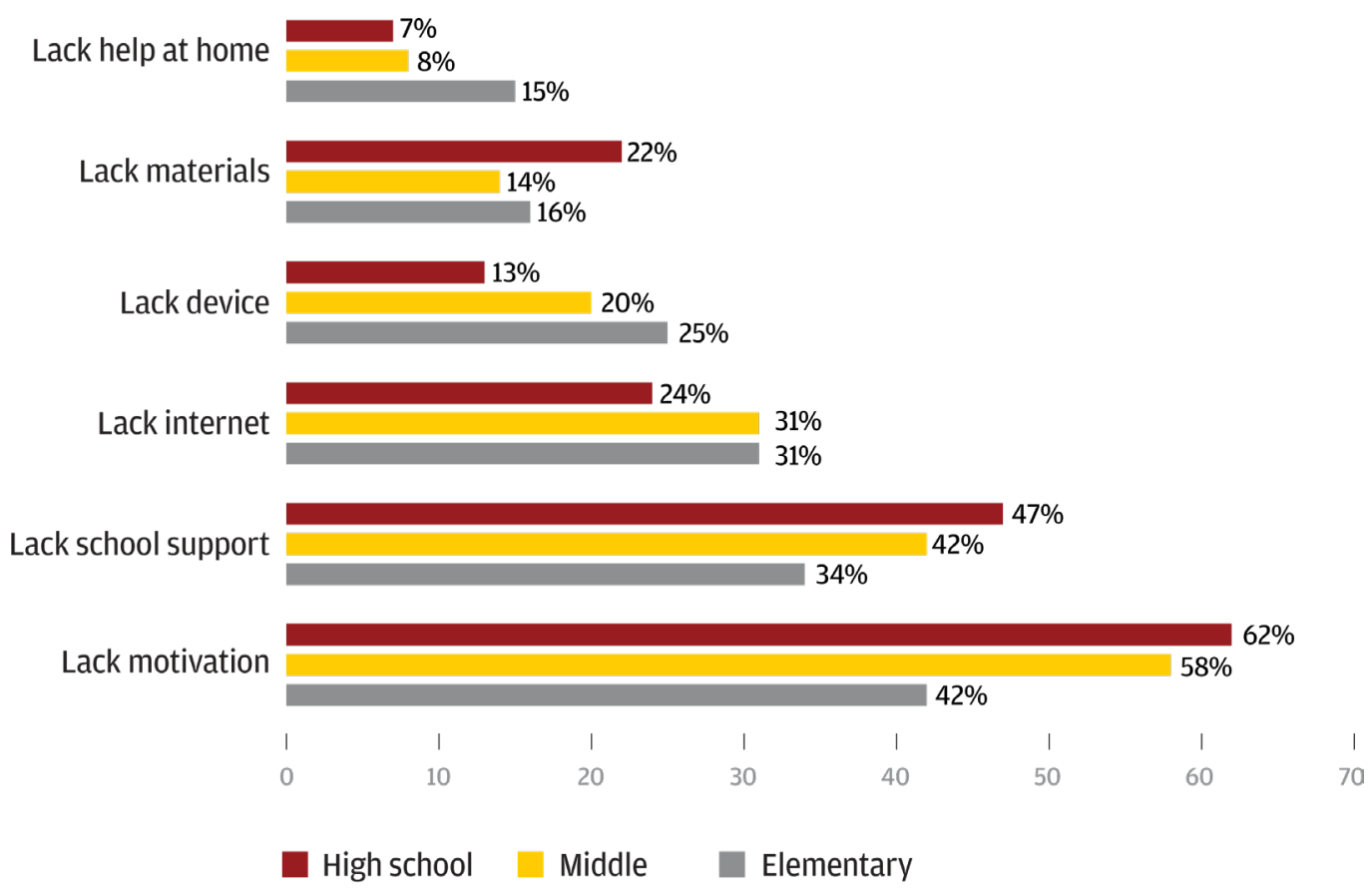




\section{Remote Learning Outcomes}

\section{Better connectivity and devices boost engagement}

Student engagement, another critical factor that affects school performance, is also affected by digital readiness at home. As shown, families equipped with PC devices and better connectivity report higher levels of engagement among students.

Has your child been able to stay engaged with school during remote learning?

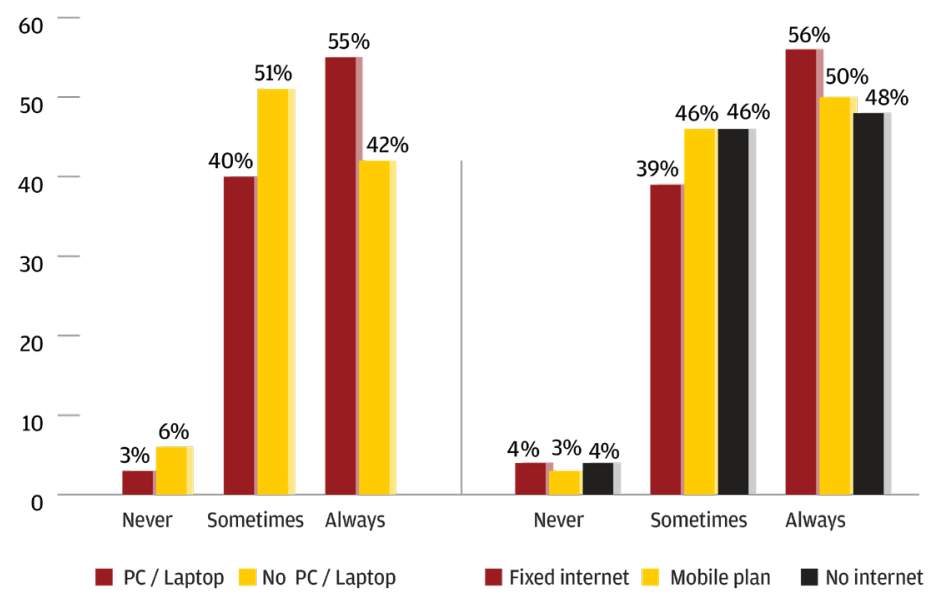

\section{STEM education is particularly challenging}

When probed about their children's experience across different school subjects, families report varying levels of satisfaction. As expected, STEM subjects are particularly challenging to deliver through remote instruction.

How would you rate your child's experience with remote learning?

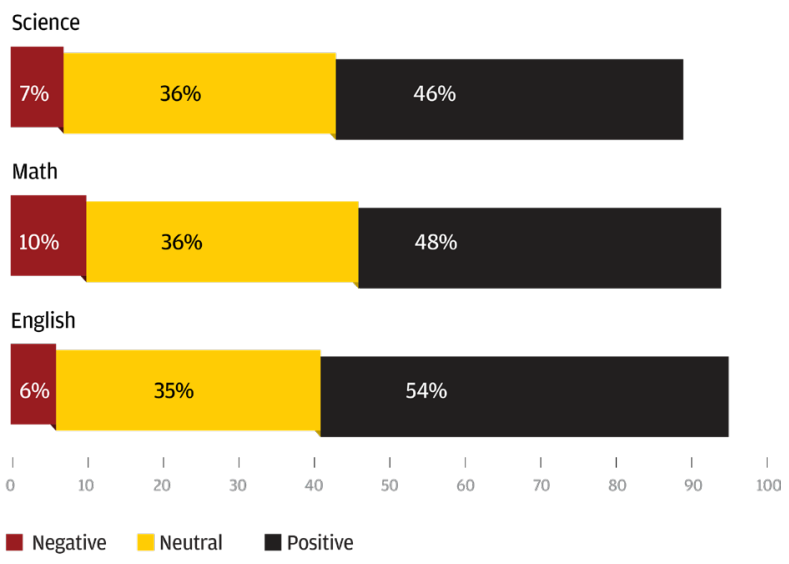




\section{Remote Learning Outcomes}

\section{Live instruction helps with math and English}

Parents reported better experience with both English and math as the number of live instruction hours increases, thus corroborating the key role that live classes play in students' remote learning experiences.

Experience with math during remote learning by hours of live instruction

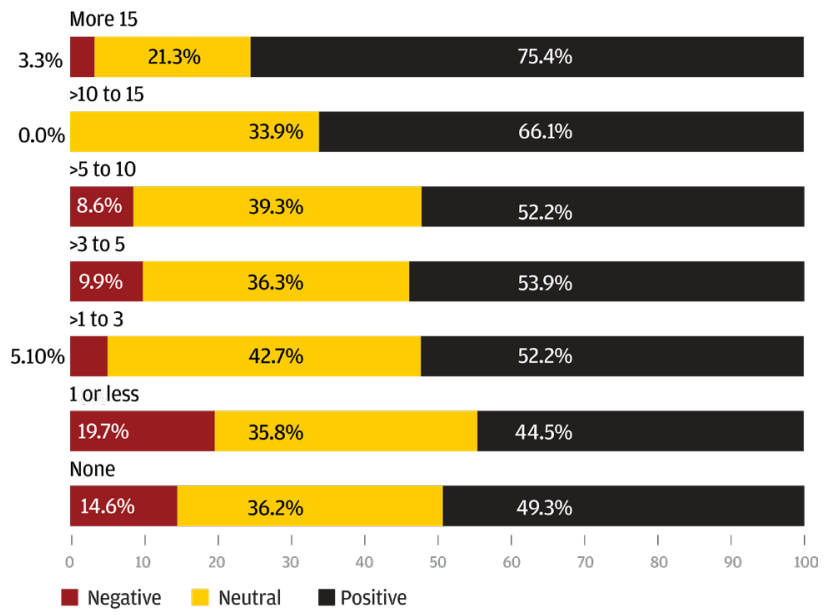

Experience with English during remote learning by hours of live instruction

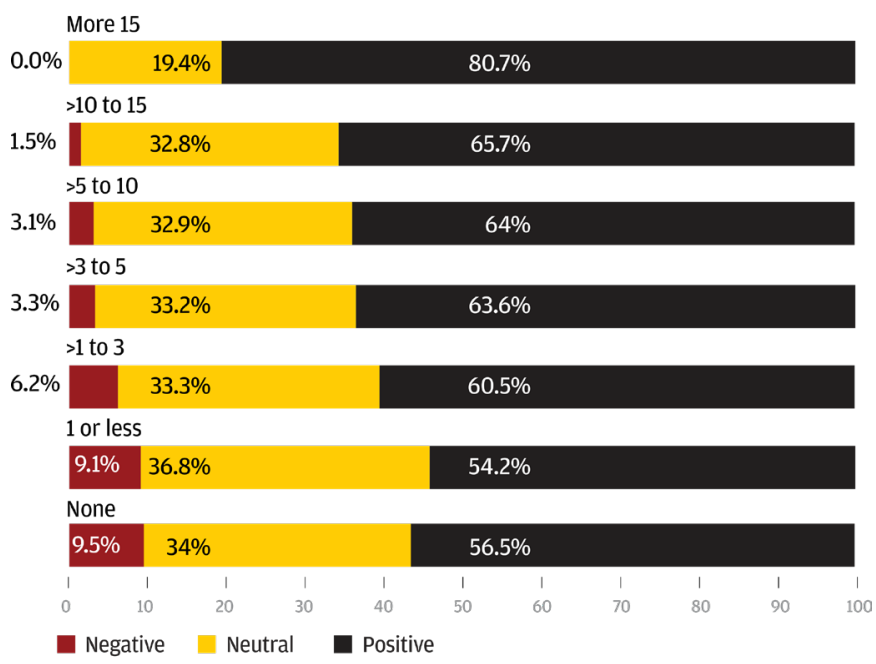




\section{Expectations for improving distance learning}

When asked about how to improve remote instruction, parents are keenly aware that digital readiness, live instruction and school engagement with families are critical components. Families thus expect schools to offer more student support, more live instruction hours and more support to families with device and Internet connectivity issues.

\section{What would you want your child's school to do in the fall to support remote learning?}

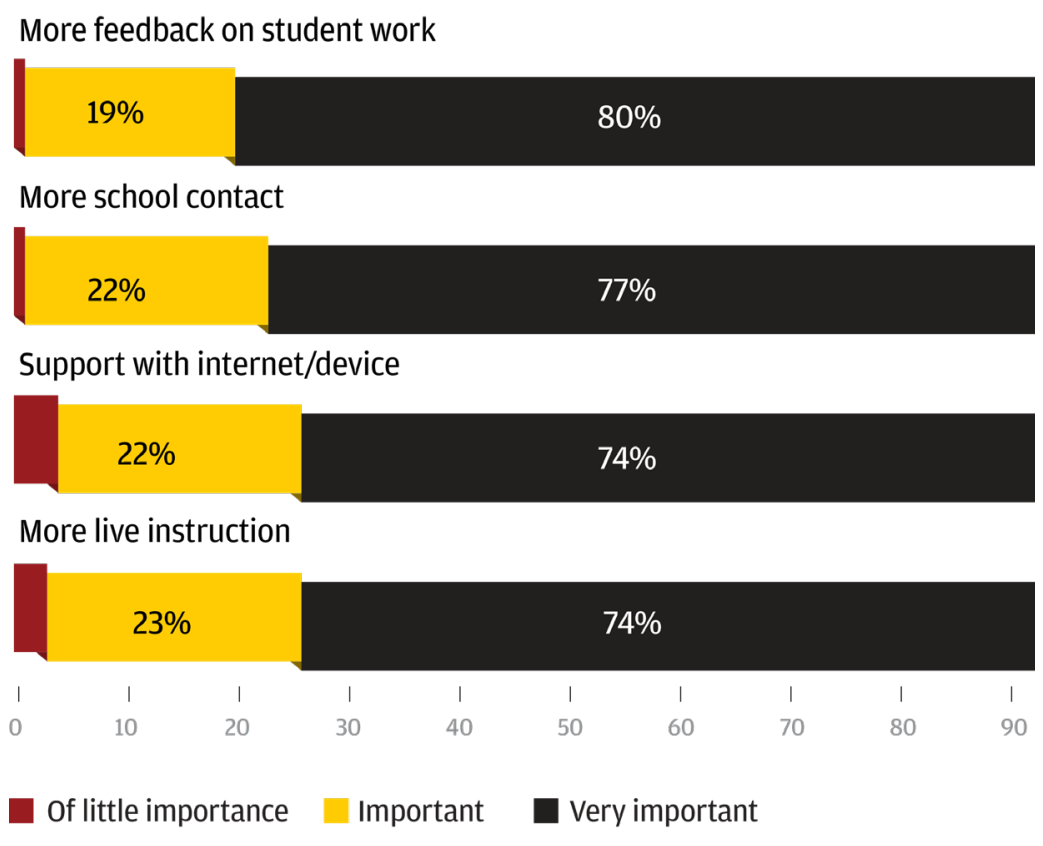




\title{
Conclusion and policy recommendations
}

\author{
Hernan Galperin \\ Associate Professor, USC Annenberg School for Communication and Journalism
}

The COVID-19 pandemic has forced the transition to distance learning for over 56 million K-12 students across the US. While all families are struggling to adapt to remote education, the findings of this study suggest that disadvantaged students and their families are bearing the brunt of the disruption to normal schooling. To begin with, low-income Black and Hispanic families have been disproportionately impacted by the health and economic fallout brought about by the pandemic. As they struggle with health risks, income losses and food insecurity, these families must also assemble the multiple resources needed to accommodate a classroom within the home.

At the most basic level, distance learning requires that each student is equipped with a computing device connected to a robust broadband service. We have long been aware that differences in digital readiness at home can affect school performance. But in the spring of 2020, what was a long-simmering problem became an emergency, with schools and families scrambling to buy laptops, wireless hotspots and other basic infrastructure for remote education.

Much progress has been made since then, and schools throughout the country are significantly better prepared to deliver remote instruction in the 2020-21 school year. However, this study also shows that an internet-enabled computer is the bare minimum. An appropriate learning space at home, support to troubleshoot devices and access online educational platforms, robust live instruction, and other ingredients are also critical to sustain motivation and avoid learning losses.

When the school comes home, pre-existing inequalities in parental wealth and human capital become front and center. However, there is much that can be done to mitigate learning losses and avoid the exacerbation of school performance gaps. A good starting point is something that has been on the agenda for decades: to make sure that every K-12 student has an internet-connected device that extends learning beyond the school campus and into the home. This is needed not just to address the current health emergency, but to strengthen schooling as a key opportunity equalizer in the 21 st century. 


\section{Reflections for community engagement research}

Eduardo Gonzalez

Ph.D. Student, USC Annenberg School for Communication and Journalism

"Lo aconsejaba motivándole que el puede hacerlo. Pero como yo no entiendo el inglés y la tecnología eso le dificulta ayudarlo."

"I would motivate him by encouraging him that he could do it. But because I don't speak English or understand how to use technology, it is difficult to help him."

\section{"Que le echara ganas en el estudio para que no tuviera un trabajo como el de los padres." "[I told my child] to work hard in their education so they can get a better job than their parents."}

As a $\mathrm{PhD}$ student and researcher, Fulbright Scholar, and first-generation Mexican-American, I am the product of K-12 education from the Los Angeles Unified School District. I envision a career as a scholar in academia that works with communities to produce work that is beneficial to economically disenfranchised, immigrant, and non-English speaking families like my own. I am grateful to have been a member of the research team for this project on how LA Unified families respond to emergency distance learning resulting from COVID-19.

As an academic researcher, I was responsible for training the outreach team on the Institutional Reviews Board (IRB) protocols and parameters, survey instructions and customs, and helped support the outreach team while they were collecting data. The outreach team had varying degrees of Spanish language proficiency, and nearly half of the outreach team members were monolingual Spanish speakers with little formal educational training and the rest of the team had learned it in the home. As a result, nearly all of the interviewers had very limited Spanish language writing competencies, and struggled with writing down respondents' answers for the open-ended questions. As a researcher, I had to be available to the team during peak calling hours to transcribe respondent answers and account for nuance.

This work produced raw and honest responses that left both our outreach team and the immigrant and non-English speaking communities we work with feeling empowered. I am currently leading a follow-up study of this project, which will conduct in-depth interviews with families who completed the survey to better understand how LAUSD students and families are responding to distance learning during the 2020-2021 academic year. Conducting community engagement research with families, like my own, is a rewarding endeavor that leaves communities feeling efficacious, valuable, and seen. 


\section{Reflections for community engagement research}

\section{Recommendations for community engagement research:}

1. Share your findings with your community: when working with non-English speaking or non-academic populations, be sure to present your findings in ways intelligible to the community you are collaborating with.

2. Be a bridge: Fill in the academic and professional gaps in experience with your research team-when doing community engagement, dedicating extra time to discussing Institutional Review Board (IRB) protocol and practices, which supports a safer environment for the interviewers and respondents.

3. Speak their language: When collecting data in a foreign language, assess their language proficiencies and work to support your research assistants or team to ensure legible and coherent data collection, thereby creating a positive and supportive environment for everyone.

4. Craft your research with care: When asking parents to speak about their children's educational experiences and learning outcomes, craft your questions such that parents can attempt to speak to them-also validating the instances where they cannot. By working with parents whose middle- and high school aged children had surpassed their own educational training, or who had limited experiences in the home because of working multiple jobs, the researchers had to create a welcome environment for parents to respond honestly-even if the answer was "I don't know."

5. Keep it open: Whether you need to include open-ended questions and/or design extra time into the analysis stage, dedicating time to collecting and translating open-ended answers allows your respondents the opportunity to verbalize any other shortcomings that were unaccounted for in your survey or interviews. This is inevitable, but being mindful your own research design's shortcomings, and allowing your respondents the chance to discuss any lingering thoughts, may result in richer data. 


\section{Using technology during community engagement in research}

Clare Baek

Ph.D. Student, USC Rossier School of Education

The USC research team aimed to examine how distance learning has been affecting students and their families economically and academically during COVID-19. Experienced survey callers from the LA Partnership, where some of them are parents of students from LAUSD schools themselves, conducted the survey through making calls to families of students from LAUSD using the survey links that were generated and provided by the USC research team.

During community engagement in research, collaboration teams might experience some challenges while working with each other. These challenges should be overcome by developing and employing strategies to ensure that research is carried out in a two-way interactive partnership with the community members. Some of these challenges involve using technology for research, more specifically, in involving both teams through using varieties of technology tools and features. Through experiencing some challenges and problem-solving while working with the callers from the community, we have learned the importance of the culturally sensitive communications and research approaches. More specifically, we have learned several lessons regarding using technology tools during this community engagement in research and we discuss recommendations for future projects.

First, it is crucial that all members of the community research team are equally familiar with the modality of the communication technology. In this study, Google Chat was used for communication between the survey callers from the LA Partnership and USC research team while the callers conducted the survey to the families. The purpose of this communication is to problem solve any technical issues (e.g., malfunctioning survey links) and clarification of the survey content (e.g., wording of some questions that may seem to confuse families being interviewed) to optimize the survey processes and results. While Google Chat was an effective tool that allowed synchronous communication between the two teams and immediate problemsolving, not all callers benefitted equally from this tool.

Some callers actively asked questions on Google Chat when there was a problem which was solved immediately by the USC research team. However, a few callers did not use Google Chat to ask questions but instead, used other methods. For example, there was a Google Doc that both teams shared which had survey links that the callers used to conduct the surveys and a few callers wrote their questions as comments on this Google Doc. The Google Doc comments notification did not get sent out immediately and the USC research team was notified of the 


\section{Using technology during community engagement in research}

existence of the comments via email several hours after. Therefore, the problems that needed immediate attention were not corrected during this particular survey session. This is an example of how the modality of the communication technology was not equally utilized by all members of the community team which inadvertently led to overlooked communication and delayed response.

The recommendation for both teams is to be aware of the callers' familiarity with technology being used during the research process. Before implementing a device for the community research team, a survey should be conducted to the callers to gauge their familiarity with the device. Following the results of this survey, there should be a brief training on using the device where both teams are present; this training will not only ensure that all callers are familiar with the features but also ensure that all members of the teams agree on the methods of communication.

Another lesson that we have learned is the importance of individual conversation between the callers and the research team when discussing sensitive topics by using the available private messaging technology features. For example, a caller who was identified by the community team as comfortable in conducting the survey in both English and Spanish might be more confident in one of the languages. The USC research team received a more accurate and honest answer when chatting privately through Google Chat with callers than chatting through the whole group messaging platform regarding the preferred language the caller wants to be assigned with.

Another example of a potentially sensitive conversation is when the USC research team checked the progress of the callers (e.g., whether the callers need more survey links or not) by messaging the whole group on Google Chat. Being aware of the whole group's progress through the group message could have put pressure on the callers who had slower pace in completing the surveys.

Therefore, the university research team should communicate with community research partners through private messaging or chatting features if topics are on potentially sensitive topics that could cause discomfort for the community members. The recommendation is for the university research team to be mindful and sensitive, and use individual communication using technology whenever applicable. 


\section{Thank You}

For their funding support

Ana Ponce, Executive Director, Great Public Schools Now
Great Public

Schools Now

Thank you to the school organizations who participated in this project

Erik Paz, Outreach team lead, Partnership for Los Angeles Schools

Gustavo Andrade, Outreach team member

Rosa Andrade, Outreach team member

Maria Andrade, Outreach team member

Mariela Morales, Outreach team member

Maria Reyes, Outreach team member

Adriana Chavez, Outreach team member

Ryan Smith, Chief External Officer

Chase Stafford, Director of Policy and Planning

Fidel Ramirez, Chief Executive Officer, Vaughn Next Century Learning Center

VAUGHN|NEET CENTURY

Emilio Pack, Chief Executive Officer, STEM Prep Schools

STEM

For your contribution to the project

Alan Arkatov, Katzman/Ernst chair for educational entrepreneurship, technology and innovation, Founder Center EDGE

USCRossier

School of Education

Center for Engagement-Driven Global Education (EDGE)

Rachel Hunt, Educational Consultant 